\title{
Does dynamic hyperinflation contribute to dyspnoea during exercise in patients with COPD?
}

\author{
Jordan A. Guenette, Katherine A. Webb and Denis E. O’Donnell
}

ABSTRACT: Dynamic hyperinflation (DH) during exercise occurs in most but not all patients with advanced chronic obstructive pulmonary disease (COPD). It is not known whether the presence or absence of DH has implications for dyspnoea and exercise tolerance. Therefore, we compared detailed ventilatory and sensory responses to exercise in hyperinflators and nonhyperinflators with moderate-to-severe COPD.

Nonhyperinflators $(n=65)$ were retrospectively identified from a sample of 427 patients and case-matched to a group of hyperinflators $(n=65)$ based on sex, age, body mass index and \% predicted forced expiratory volume in $1 \mathrm{~s}$. Resting pulmonary function and constant work rate cycle exercise responses were compared.

Hyperinflators decreased inspiratory capacity (IC) from rest to peak exercise by $0.46 \pm 0.24 \mathrm{~L}$ whereas the nonhyperinflators increased IC by $0.10 \pm 0.15 \mathrm{~L}(\mathrm{p}<0.0001)$. There were no significant group differences in endurance time $(9.11 \pm 5.98$ versus $8.87 \pm 5.24 \mathrm{~min})$ or dyspnoea intensity for any given time or ventilation. An inflection in tidal volume versus ventilation occurred in the majority of nonhyperinflators $(n=61)$ and hyperinflators $(n=62)$ at a similar time and ventilation. Mechanical constraints on tidal volume expansion and the attendant rise in dyspnoea intensity were similar in both groups.

Dyspnoea intensity during exercise was associated with progressive mechanical constraints on tidal volume expansion regardless of the presence of $\mathrm{DH}$.

KEYWORDS: Chronic obstructive pulmonary disease, inspiratory capacity, inspiratory reserve volume

I n patients with chronic obstructive pulmonary disease (COPD), dyspnoea (or breathing discomfort) arises in any situation where there is a disparity between the central drive to breathe and the mechanical response of the respiratory system, i.e. neuromechanical uncoupling [1-3]. Resting lung hyperinflation and reduced inspiratory capacity (IC) predispose to critical mechanical constraints on tidal volume $(V \mathrm{~T})$ expansion as ventilatory requirements increase during exercise. An inflection or plateau in the $V \mathrm{~T}$ response to exercise, when expressed as a function of increasing ventilation, occurs at a minimal dynamic inspiratory reserve volume (IRV) of 0.5-1.0 L. This mechanical event marks the beginning of a progressive disparity between respiratory muscle effort (i.e. tidal oesophageal pressure relative to maximum inspiratory pressure) and the corresponding $V$ T response (relative to vital capacity) [3]. This increasing neuromechanical uncoupling is associated with an abrupt increase in dyspnoea intensity, which is predominantly perceived as unsatisfied inspiration [1, 3]. The smaller the IC, the lower the minute ventilation $\left(V^{\prime} \mathrm{E}\right)$ during exercise at which the $V$ T reaches its plateau and the earlier the onset of intolerable dyspnoea [2].

Traditionally, dynamic hyperinflation $(\mathrm{DH})$ refers to the variable and temporary increase in endexpiratory lung volume (EELV) above its baseline value which occurs when ventilatory demand is acutely increased. This is usually measured by serial IC manoeuvres which accurately reflect changes in EELV provided that total lung capacity (TLC) remains unaltered. This is to be distinguished from changes in end-inspiratory lung volume (EILV), which represents the combination

\section{AFFILIATIONS}

Respiratory Investigation Unit, Dept of Medicine, Queen's University and Kingston General Hospital, Kingston, ON, Canada.

\section{CORRESPONDENCE}

J.A. Guenette

Respiratory Investigation Unit

Queen's University and Kingston

General Hospital

76 Stuart Street

Kingston

ON

K7L-2V7

Canada

E-mail: guenette@queensu.ca

Received:

Sept 122011

Accepted after revision:

Dec 092011

First published online:

Dec 192011 
of change in EELV and expansion of $V \mathrm{~T}$, and is therefore not a measure of $\mathrm{DH}$. The specific contribution of $\mathrm{DH}$ and the consequent progressive erosion of dynamic IC to dyspnoea causation during exercise is unclear and is the main focus of this study. In population samples of patients with moderate-tosevere COPD, a decrease in rest to peak IC was reported in the majority of patients $(80-85 \%)[4,5]$. Smaller studies employing optoelectronic plethysmography have identified varied behaviour of end-expiratory chest wall motion during exercise and have designated subgroups of COPD as nonhyperinflators ("euvolemics") [6] and "early" and "late" hyperinflators [7].

The mechanical consequences of $\mathrm{DH}$ during exercise are complex. In many patients the largest increase in dynamic EELV occurs within the first few minutes of exercise where dyspnoea ratings are generally only in the mild-to-moderate range [3]. $\mathrm{DH}$ at these lower exercise intensities attenuates expiratory flow limitation which helps to preserve neuromechanical coupling of the respiratory system [3]. However, it is also possible that progressive erosion of dynamic IC during exercise in hyperinflators will force an earlier $V$ T plateau with attendant increase in dyspnoea at a lower $V^{\prime} \mathrm{E}$ than in nonhyperinflators. Moreover, it is known that further acuteon-chronic lung hyperinflation has other potentially negative pulmonary and cardiovascular consequences, as recently reviewed [8].

Given the variable mechanical consequences of $\mathrm{DH}$, its specific contribution to perceived respiratory discomfort during physical activity in COPD is difficult to predict. For example, improvement in dyspnoea ratings after bronchodilator therapy is more closely associated with reductions in absolute lung volumes (or increase in $V \mathrm{~T}$ and IRV) than with reduction of $\mathrm{DH}$ which is often unaffected or, in some cases, may even increase modestly [9-11].

The main purpose of this study was to determine the direct contribution of $\mathrm{DH}$ to dyspnoea and exercise intolerance in COPD. We therefore compared breathing pattern, time to the $V \mathrm{~T}$ plateau/minimal IRV, dyspnoea/IRV relationships and endurance time in hyperinflators and nonhyperinflators matched for severity of airway obstruction, age, sex, and body mass index (BMI). We reasoned that the finding of an earlier onset of critical mechanical constraints on $V \mathrm{~T}$ expansion and corresponding increase in dyspnoea in hyperinflators would support the notion that $\mathrm{DH}$ of itself has important negative sensory consequences in COPD.

\section{METHODS}

\section{Subjects and study design}

This study is a retrospective analysis of exercise data from a large group $(n=427)$ of COPD patients that participated in two multicentre clinical trials examining the effects of tiotropium on exercise tolerance $[12,13]$. It does not overlap with previous analyses of the same data set $[2,14,15]$. Ethical approval was obtained by all research sites and patients gave informed written consent prior to participation. The Research Ethics Board of Queen's University and Affiliated Teaching Hospitals (Kingston, ON, Canada) approved the use of these data (DMED-1424-11).

Original inclusion criteria were as follows: $40-75$ yrs of age, cigarette smoking history $>10$ pack-yrs, plethysmographic functional residual capacity (FRC) $>120 \%$ predicted and a forced expiratory volume in $1 \mathrm{~s}$ (FEV1) $\leqslant 65 \%$ pred. Subjects were excluded if they had a history of asthma, allergic rhinitis or atopy, any contraindication to clinical exercise testing and/ or participation in a COPD rehabilitation programme within 6 weeks prior to the screening visit.

Subjects were required to refrain from using long-acting bronchodilators for a minimum of 1 week prior to and throughout the duration of the study. Short-acting anticholinergics were withdrawn a minimum of 1 day prior to the screening visit and were not used throughout the study. Salbutamol was given as rescue medication during the study but was withdrawn $\geqslant 6 \mathrm{~h}$ prior to each visit.

Detailed pulmonary function testing and an incremental symptom-limited cycle exercise test were performed during a screening visit which was followed by two run-in visits whereby subjects performed pulmonary function tests and a symptom-limited constant work rate cycle test. Exercise and pulmonary function data analysis were based upon the second run-in visit. DH was defined as a decrease in IC from rest of more than $150 \mathrm{~mL}$ or $4.5 \%$ pred at any time-point during exercise [4]. O'DONNELL et al. [4] previously demonstrated that the $95 \%$ CI for the resting IC measurement was $\pm 0.14 \mathrm{~L}$ or $\pm 4.5 \%$ pred in patients with COPD, indicating that reproducibility criteria of within $150 \mathrm{~mL}$ are appropriate for testing IC in this population. Importantly, the $95 \%$ CI for peak exercise IC was similar. Subjects were then divided into two subgroups based on the presence or absence of $\mathrm{DH}$. After identifying all nonhyperinflators $(n=65)$, experimenters systematically matched them to 65 of the remaining 362 hyperinflators based on sex, \% pred FEV1, age and BMI, while remaining blinded to all other measurements. Matching was randomly determined if more than one hyperinflator was a suitable match to a nonhyperinflator.

\section{Pulmonary function}

Spirometry and body plethysmography were performed according to established guidelines and values are expressed as \% pred. Predicted IC was calculated as predicted TLC minus predicted FRC, since there are no current equations for predicting normal IC. Maximal ventilatory capacity (MVC) was estimated by multiplying FEV1 by 35 [16].

\section{Exercise tests}

Details regarding the incremental cycle test have been described elsewhere [12]. The constant work rate exercise test involved a steady-state rest period and a 1-min warm up at $0 \mathrm{~W}$ followed immediately by an increase in work rate corresponding to $75 \%$ of the peak incremental work rate until symptom limitation. Time from the onset of this work rate to symptom limitation was defined as the endurance time. Metabolic and ventilatory parameters were measured on a breath-by-breath basis using various commercially available systems. Intensities of dyspnoea and leg discomfort were assessed using the modified Borg scale [17]. Borg ratings and IC manoeuvres were performed at rest, throughout exercise, and at symptom limitation. IC manoeuvres were used to examine operating lung volumes and $\mathrm{DH}$ as previously described [18]. Data are presented as 30-s averages during rest, the last $30 \mathrm{~s}$ of each second minute during exercise, and at peak exercise. The inflection point of $V \mathrm{~T}$ relative to $V^{\prime} \mathrm{E}$ 
during exercise was also determined for each subject using the 30-s averaged data at each time-point [19].

\section{Statistical analysis}

Data are presented as mean \pm SD unless otherwise specified. Reasons for stopping exercise were analysed as frequency statistics and compared using the Fisher's exact test. Betweengroup comparisons (nonhyperinflators vrsus hyperinflators) for descriptive characteristics and exercise responses at standardised times were performed using unpaired t-tests. P-values $<0.05$ were regarded as statistically significant.

\section{RESULTS}

\section{Subject characteristics}

$65(15 \%)$ out of 427 subjects were identified as nonhyperinflators. Characteristics of the nonhyperinflators and the matched hyperinflators $(n=65)$ are shown in table 1. By design, both groups were closely matched for FEV1 (\% pred and L), age, BMI and sex. The hyperinflators had a larger forced vital capacity (FVC) resulting in a slightly lower FEV1/ FVC ratio. Hyperinflators also had greater \% pred values for TLC and FRC compared with the nonhyperinflators. There were no significant differences between groups in peak incremental work rate and oxygen uptake $\left(V^{\prime} \mathrm{O}_{2}\right)$.

\section{Exercise responses}

Physiological and perceptual responses at the $V \mathrm{~T}$ inflection point and at peak exercise are summarised in table 2. Both groups were well matched for absolute work rate during the constant work rate cycling test with no significant differences in cycle endurance time or peak $V^{\prime} \mathrm{O}_{2}$.

The change in dynamic IC from rest to peak exercise (i.e. the inverse magnitude of $\mathrm{DH}$ ) was $-0.46 \pm 0.24 \mathrm{~L}$ in the hyperinflators and $0.10 \pm 0.15 \mathrm{~L}$ in the nonhyperinflators (fig. 1a; table 2). IC in the hyperinflators decreased rapidly (by $0.34 \pm 0.23 \mathrm{~L}$ ) within the first 2 min of exercise and continued to decrease, albeit less abruptly, until symptom limitation (fig. 1). In contrast, the nonhyperinflators increased IC modestly (by $0.10 \pm 0.28 \mathrm{~L}$ ) at the onset of exercise and then maintained this level throughout exercise. The steady-state resting IC immediately prior to exercise was lower in the nonhyperinflators (fig. S1).

Selected exercise responses are shown in fig. 2. There were no significant differences between groups for $V^{\prime} \mathrm{O}_{2}, V^{\prime} \mathrm{E}$, respiratory frequency or $V \mathrm{~T}$ at any given time throughout exercise. An inflection point in the relationship between $V \mathrm{~T}$ and $V^{\prime} \mathrm{E}$ occurred in the majority of nonhyperinflators (61 out of 65) and hyperinflators (62 out of 65). This inflection point occurred at a similar time, $V^{\prime} \mathrm{O}_{2}, V^{\prime} \mathrm{E}, V \mathrm{~T}$ and IRV in each group (table 2). After the $V \mathrm{~T} / V^{\prime} \mathrm{E}$ inflection point where IRV had reached a critically reduced level in both groups, there was no further change in $V \mathrm{~T}$ during exercise, i.e. there was a plateau (fig. 3).

\section{Exertional dyspnoea}

The main reasons for stopping constant work rate exercise were similar in both groups: dyspnoea was selected as the primary reason, either alone or in combination with leg discomfort, in 51 out of 65 and 53 out of 65 of nonhyperinflators and hyperinflators, respectively. No significant differences in dyspnoea intensity were observed at any given exercise time or $V^{\prime}$ E during constant work rate cycling (fig. 4).
Likewise, no differences in dyspnoea intensity were observed at the $V \mathrm{~T}$ inflection point (table 2). Dyspnoea intensity increased linearly as IRV decreased in both groups up to an inflection point (corresponding to the $V \mathrm{~T} / V^{\prime} \mathrm{E}$ inflection point) where subjects reported "moderate" exertional dyspnoea. Beyond this point, and irrespective of the presence of $\mathrm{DH}$, dyspnoea as a function of IRV increased steeply to intolerable levels where patients reported "very severe" dyspnoea at the symptomlimited end-point (fig. 4c).

A secondary analysis comparing the nonhyperinflators $(n=65)$ to all hyperinflators $(n=362)$ whereby groups were not systematically matched for any baseline characteristics, revealed similar results for our primary outcomes (i.e. no group differences in dyspnoea or cycle endurance time).

\section{TABLE 1 Subject characteristics}

\begin{tabular}{|c|c|c|}
\hline Characteristics & Nonhyperinflators & Hyperinflators \\
\hline Subjects (male/female) $n$ & $65(44 / 21)$ & $65(44 / 21)$ \\
\hline Age yrs & $60 \pm 7$ & $62 \pm 7$ \\
\hline Height $\mathrm{cm}$ & $171 \pm 8$ & $170 \pm 9$ \\
\hline Mass kg & $73.5 \pm 18.4$ & $74.6 \pm 15.6$ \\
\hline $\mathrm{BMI} \mathbf{k g} \cdot \mathrm{m}^{-2}$ & $25.1 \pm 5.6$ & $25.7 \pm 4.2$ \\
\hline Smoking history pack-yrs & $48.1 \pm 23.5$ & $48.9 \pm 25.3$ \\
\hline Duration of COPD yrs & $9.8 \pm 8.0$ & $7.8 \pm 6.4$ \\
\hline FEV 1 L & $1.41 \pm 0.45$ & $1.38 \pm 0.47$ \\
\hline FEV $1 \%$ pred & $50 \pm 14$ & $50 \pm 13$ \\
\hline FVC L & $2.78 \pm 0.79$ & $2.96 \pm 0.79$ \\
\hline FVC \% pred & $70 \pm 16$ & $76 \pm 15^{*}$ \\
\hline $\mathrm{FEV}_{1 / F V C} \%$ & $51.1 \pm 10.9$ & $46.7 \pm 11.1^{*}$ \\
\hline $\mathrm{FEV}_{1 / \mathrm{FVC}} \%$ pred & $71 \pm 16$ & $66 \pm 15.3^{*}$ \\
\hline FEF25-75\% L.s ${ }^{-1}$ & $0.61 \pm 0.37$ & $0.52 \pm 0.29$ \\
\hline FEF25-75\% \% pred & $21 \pm 12$ & $18 \pm 9$ \\
\hline IC L & $2.16 \pm 0.62$ & $2.22 \pm 0.68$ \\
\hline IC \% pred & $75 \pm 18$ & $78 \pm 20$ \\
\hline IC/TLC & $30.6 \pm 7.5$ & $29.9 \pm 7.6$ \\
\hline TLC L & $7.08 \pm 1.17$ & $7.50 \pm 1.52^{\#}$ \\
\hline TLC \% pred & $115 \pm 15$ & $122 \pm 16^{*}$ \\
\hline FRC L & $4.92 \pm 1.00$ & $5.27 \pm 1.28^{\#}$ \\
\hline FRC $\%$ pred & $151 \pm 30$ & $161 \pm 33^{\circ}$ \\
\hline RV L & $4.12 \pm 1.00$ & $4.29 \pm 1.20$ \\
\hline RV \% pred & $196 \pm 48$ & $201 \pm 49$ \\
\hline Raw $\mathrm{cmH}_{2} \mathrm{O} \cdot \mathrm{L}^{-1} \cdot \mathrm{s}^{-1}$ & $5.58 \pm 2.72$ & $5.46 \pm 2.04$ \\
\hline Raw \% pred & $425 \pm 215$ & $413 \pm 155$ \\
\hline Wpeak W & $81 \pm 28$ & $86 \pm 32$ \\
\hline Wpeak \% pred & $55 \pm 20$ & $58 \pm 17$ \\
\hline$V^{\prime} O_{2}$, peak L'min ${ }^{-1}$ & $1.25 \pm 0.41$ & $1.27 \pm 0.47$ \\
\hline$V^{\prime} \mathrm{O}_{2}$,peak $\mathrm{mL} \cdot \mathrm{kg}^{-1} \cdot \mathrm{min}^{-1}$ & $17.2 \pm 4.9$ & $16.9 \pm 4.8$ \\
\hline$V^{\prime} \mathrm{O}_{2}$, peak $\%$ pred & $65 \pm 23$ & $67 \pm 18$ \\
\hline
\end{tabular}

Data are presented as mean $\pm S D$, unless otherwise stated. BMI: body mass index; COPD: chronic obstructive pulmonary disease; FEV1: forced expiratory volume in $1 \mathrm{~s}$; \% pred: \% predicted; FVC: forced vital capacity; FEF25-75\%: forced expiratory flow at $25-75 \%$ of FVC; IC: inspiratory capacity; TLC: total lung capacity; FRC: functional residual capacity; RV: residual volume; Raw: airway resistance; Wpeak: peak incremental cycle work rate; $V^{\prime} \mathrm{O}_{2}$, peak: peak oxygen uptake. ${ }^{*}: p<0.05 ;{ }^{*}: p=0.08 ;{ }^{`}: p=0.05$, all $p$-values between groups. 
TABLE 2 Measurements during exercise at the tidal volume $(V T) /$ minute ventilation $\left(V^{\prime} E\right)$ inflection point and at symptom-limited peak exercise

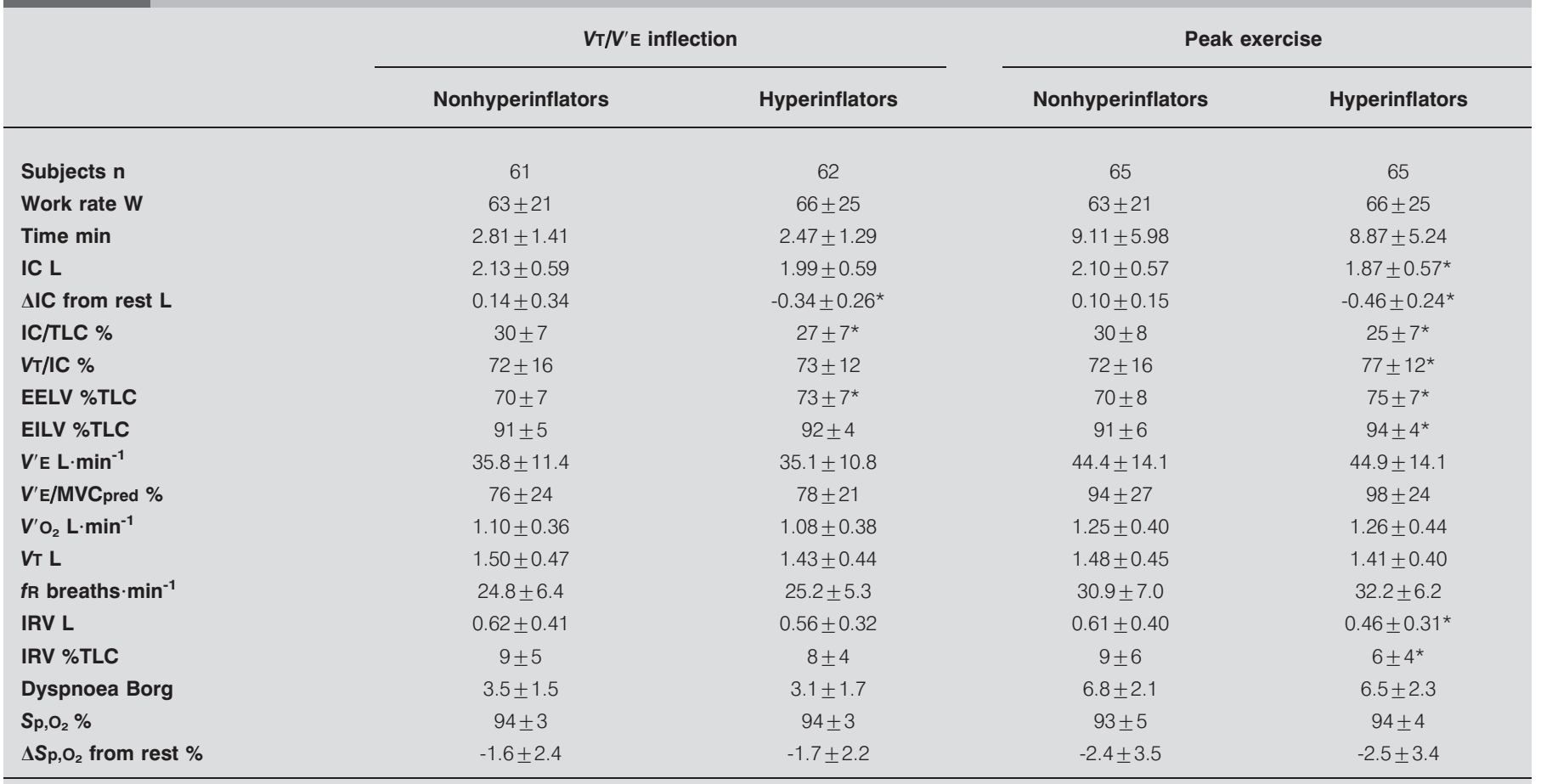

Data are presented as mean \pm SD, unless otherwise stated. Inflection data are from subjects with a detectable $V T$ inflection and peak data are from all subjects. IC inspiratory capacity; TLC: total lung capacity; EELV: end-expiratory lung volume; EILV: end-inspiratory lung volume; MVCpred; predicted maximal ventilatory capacity based on forced expiratory volume in $1 \mathrm{~s}$ multiplied by $35 ; \mathrm{V}^{\prime} \mathrm{O}_{2}$ : oxygen uptake; fR: respiratory frequency; IRV: inspiratory reserve volume; $\mathrm{Sp}, \mathrm{O}_{2}$ : arterial oxygen saturation measured by pulse oximetry. ${ }^{*}: p<0.05$ between groups.

\section{DISCUSSION}

The main findings of this study are as follows: 1) patients who acutely increased EELV during exercise did not experience higher exertional dyspnoea ratings or greater exercise intolerance compared with FEV1-matched patients who did not increase dynamic EELV; 2) hyperinflators and nonhyperinflators reached critical constraints on $V \mathrm{~T}$ expansion at a similarly reduced dynamic IRV and at a similar time and $V^{\prime}$ E during constant work rate
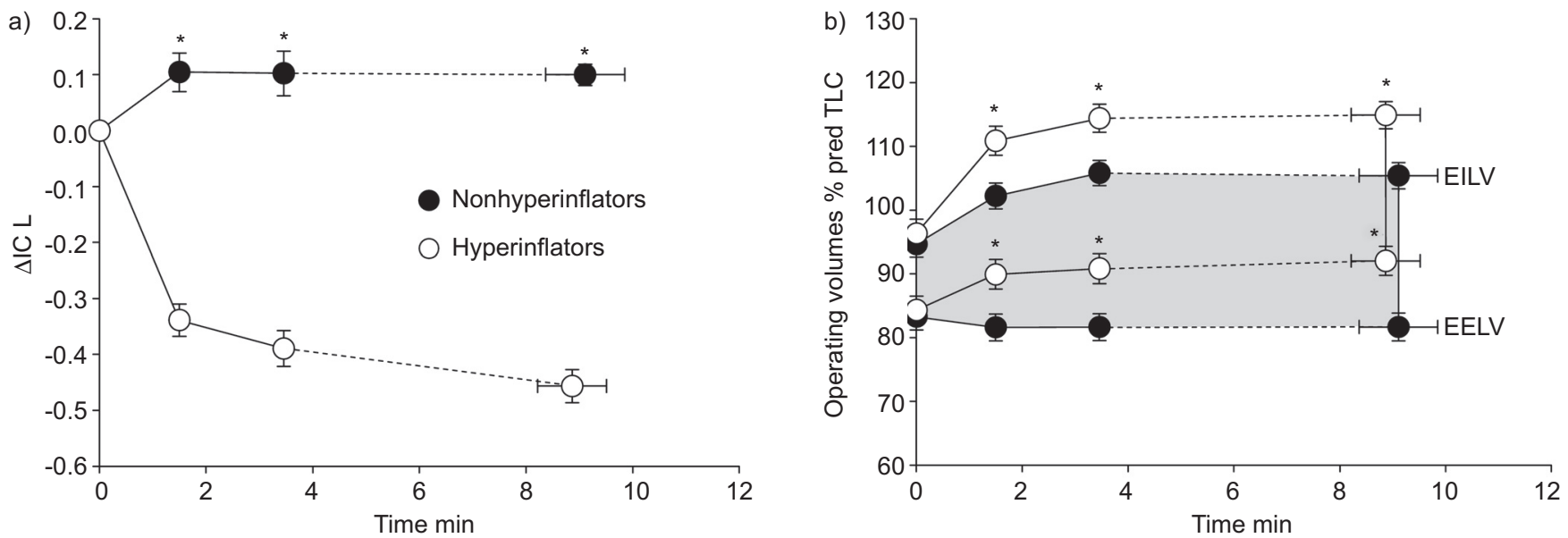

FIGURE 1. a) Change in inspiratory capacity $(\Delta \mid \mathrm{C})$ from rest and b) operating lung volumes are plotted against constant work rate exercise time in hyperinflators and nonhyperinflators. Total lung capacity (TLC) in the hyperinflators and nonhyperinflators was 122 and $115 \%$ predicted (\% pred), respectively. Data are presented as mean \pm SE. Dashed lines are from the last standardised measurement time to peak exercise. The shaded region represents tidal volume in the nonhyperinflators. EELV: end-expiratory lung volume; EILV: end-inspiratory lung volume. ${ }^{*}: \mathrm{p}<0.05$ significant difference between groups at a given time-point. IC responses in litres can be found in the online supplement. 

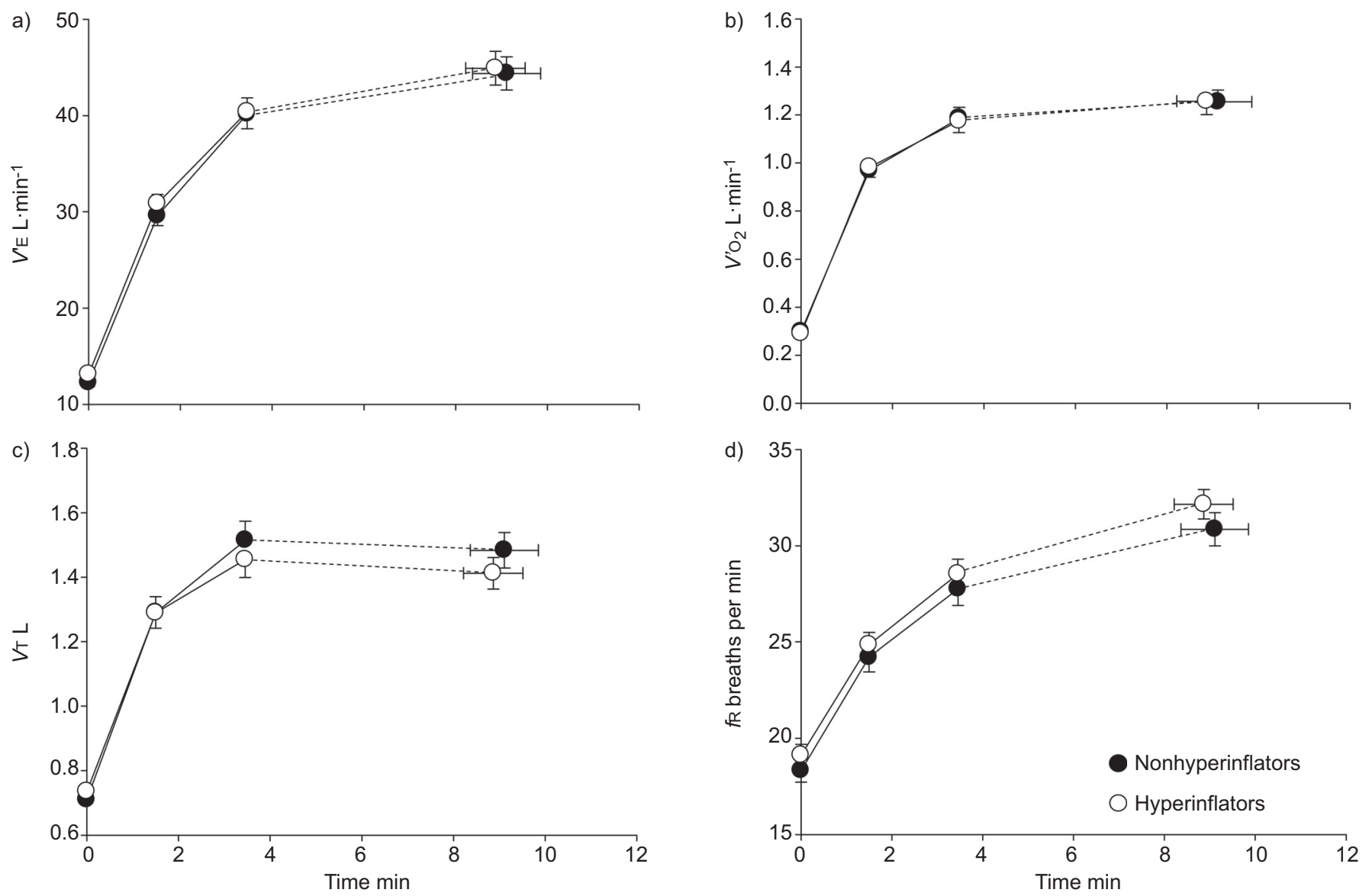

FIGURE 2. a) Minute ventilation $\left(V^{\prime} E\right)$, b) oxygen uptake $\left(V^{\prime} O_{2}\right)$, C) tidal volume $(V T)$ and d) respiratory frequency (fR) versus constant work rate exercise time in hyperinflators and nonhyperinflators. Data are presented as mean $\pm \mathrm{SE}$. Dashed lines are from the last standardised measurement time to peak exercise.

cycle exercise; and 3) dyspnoea/IRV and dyspnoea/ $V^{\prime}$ E relationships were not altered by the presence of DH.

The results of this study coupled with those of others $[4,5,20]$ suggest that approximately $15-20 \%$ of patients with moderate to severe COPD do not consistently increase EELV during

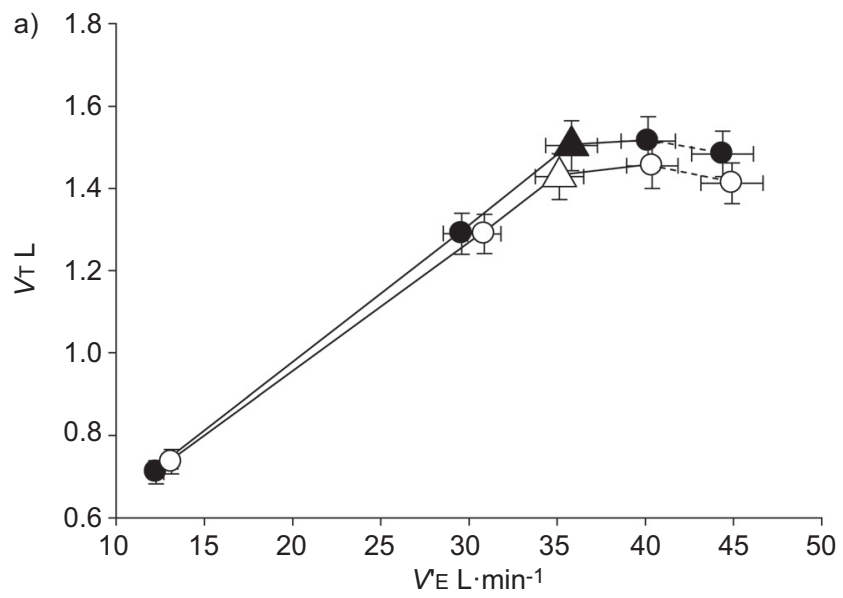

exercise. Out of 427 patients in the present study, we identified 65 patients who did not meet our conservative definition of $\mathrm{DH}$ [4]. After carefully matching subgroups of hyperinflators and nonhyperinflators for disease severity, age, sex and BMI, we observed that those who did not increase dynamic EELV during exercise had a slightly higher FEV1/FVC ratio and less

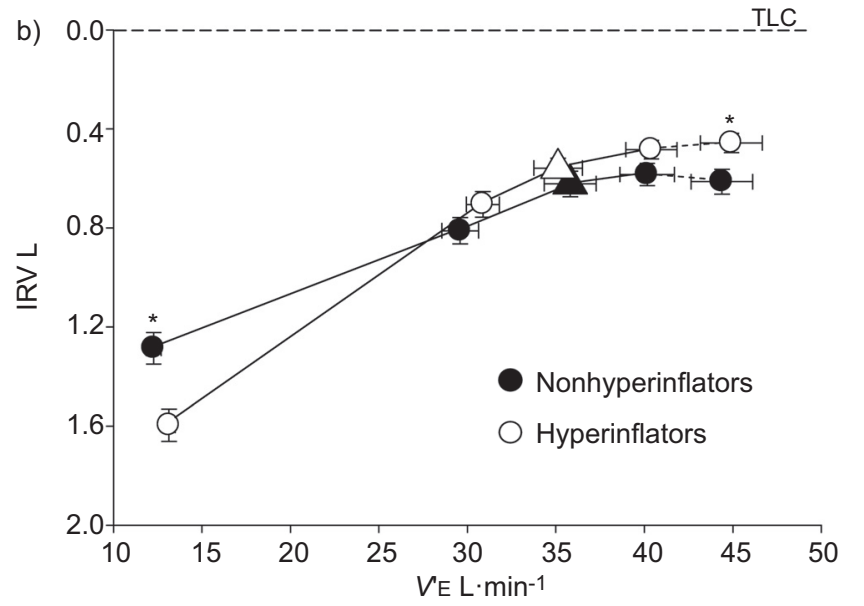

FIGURE 3. a) Tidal volume ( $V T)$ and b) inspiratory reserve volume (IRV) versus minute ventilation $\left(V^{\prime} E\right)$ in hyperinflators and nonhyperinflators. Data are presented as mean \pm SE. Dashed lines are from the last standardised measurement time to peak exercise. Triangles represent data at the $V T / V^{\prime} E$ inflection. TLC: total lung capacity. *: $p<0.05$. 

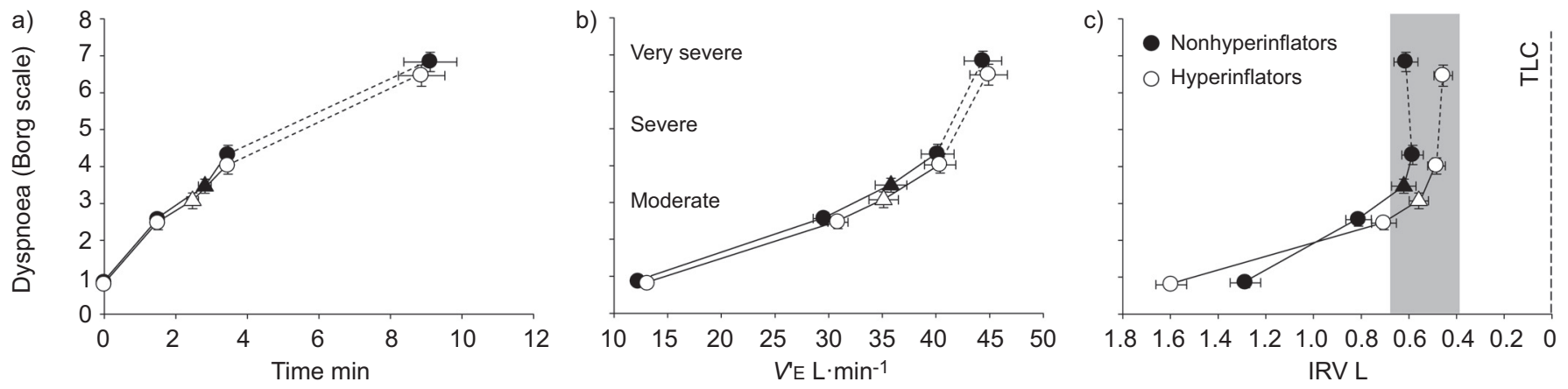

FIGURE 4. Dyspnoea versus a) constant work rate exercise time, b) minute ventilation $\left(V^{\prime} E\right)$ and c) inspiratory reserve volume (IRV) in hyperinflators and nonhyperinflators. Data are presented as mean \pm SE. Dashed lines are from the last standardised measurement time to peak exercise. Triangles represent data at the tidal volume inflection point. Shaded region represents the critical or minimal IRV where dyspnoea intensity ratings deviate from linearity and increase vertically. The Borg scale categories of very severe, severe and moderate refer to scores of more than 3,5 and 7 , respectively. TLC: total lung capacity.

resting lung hyperinflation, suggesting less airway dysfunction than the group who hyperinflated (table 1). Given that ventilatory demand and the volume and timing components of breathing during exercise were similar in both groups, we can assume that differences in EELV behaviour during exercise primarily reflected unmeasured differences in mechanical time constants for lung emptying.

The fact that patients in each group were well matched for several key parameters that influence respiratory mechanics allowed us to evaluate the role of $\mathrm{DH}$ in contributing to dyspnoea and exercise intolerance in COPD. We found that, contrary to our original hypothesis, the presence of DH was not associated with increased dyspnoea ratings or greater exercise intolerance. ALIVERTI et al. [6] recently measured operating lung volumes by optoelectronic plethysmography in patients with moderate-to-severe COPD. As in the current study, dyspnoea ratings during a symptom-limited incremental cycle test were similar in eight nonhyperinflators and 12 hyperinflators who were not matched for spirometric or anthropometric parameters. However, despite having better baseline spirometry, and in contrast to our results, the nonhyperinflators had diminished exercise performance. This discrepancy in results between the current and previous studies is probably related to differences in methods of measurement of $\mathrm{DH}$ and in exercise protocols.

The relative importance of $\mathrm{DH}$ in contributing to the intensity and quality of dyspnoea during exercise in COPD has been difficult to determine. Previous studies have shown that besides increased dynamic EELV, several indices of dynamic mechanical constraint have correlated, albeit variably, with dyspnoea intensity during exercise; these include increases in EILV and the $V \mathrm{~T} / \mathrm{IC}$ ratio and decreases in dynamic IRV, as recently reviewed [21]. In addition to correlative evidence, specific therapeutic interventions can be used to manipulate $\mathrm{DH}$ and its mechanical consequences. For example, low-level continuous positive airway pressure therapy, which is thought to counterbalance the negative effects of the inspiratory threshold load, has been shown to reduce dyspnoea and improve exercise endurance in selected patients with COPD $[22,23]$. Similarly, improvement in dyspnoea and endurance time following helium-oxygen therapy has been associated with a reduction in the rate of $\mathrm{DH}[24,25]$. In contrast, dyspnoea reduction following bronchodilator therapy, hyperoxia and exercise training have been shown to occur in the absence of a reduced rate of $\mathrm{DH}$, confirming the multifactorial nature of this symptom [9-11, 26, 27]. It is possible that other mechanical improvements following these interventions, such as reduced absolute lung volumes with a delay in reaching critical ventilatory constraints, are more important in explaining dyspnoea relief than small or inconsistent reductions in the rate of $\mathrm{DH}$. It is also noteworthy that increases in EELV in the hyperinflator group tended to occur early during highintensity constant work rate exercise: $69 \%$ of hyperinflators showed an average decrease in IC of $0.2 \mathrm{~L}$ in the first $2 \mathrm{~min}$ of exercise where perceived dyspnoea intensity was only "slight" at 2.4 Borg units.

In keeping with previous studies, a discernible inflection or plateau in the $V \mathrm{~T} / V^{\prime} \mathrm{E}$ relationship during exercise occurred in nearly all $(\sim 95 \%)$ of our study patients. This occurred regardless of whether they hyperinflated (fig. 3a). Beyond this $V \mathrm{~T}$ inflection (at a minimal IRV of $0.5-1 \mathrm{~L}$ ), dyspnoea rose sharply to intolerable levels (fig. 4c). We have previously proposed that the magnitude of the resting IC and the decrease in dynamic IRV during exercise importantly influence the evolution of dyspnoea in COPD [1, 2]. The current study suggests that dyspnoea rises as $V$ T expands to reach a minimal IRV regardless of whether IC remains stable (nonhyperinflators) or diminishes (hyperinflators) during exercise. Thus, the regulation of end-inspiration relative to TLC probably provides a more proximate measure of the critical mechanical constraints during exercise relevant to dyspnoea provocation than the behaviour of EELV per se. For example, the difference in IC from rest to peak exercise between the two groups was $0.56 \mathrm{~L}$; change in EELV in excess of $0.5 \mathrm{~L}$ would be expected to increase inspiratory threshold loading of the inspiratory muscles and, of itself, may have negative sensory consequences [23]. The results of the current study suggest other mechanical factors are more important. In both groups, EILV from the $V \mathrm{~T} / V^{\prime} \mathrm{E}$ inflection to peak was $>90 \%$ of TLC (table 2). Breathing at this high EILV is difficult to sustain given the associated increased elastic loading and functional respiratory muscle weakness [28]. This is further compounded by increased velocity of shortening of the inspiratory muscles and decreased dynamic lung compliance. At this point, central 
neural drive has reached near-maximal levels as a result of metabolic and possibly respiratory acidosis in some and $V \mathrm{~T}$ expansion is critically constrained. We have argued that this progressive neuromechanical uncoupling of the respiratory system after reaching maximal EILV provokes intolerable dyspnoea which, in many patients with COPD, is the proximate cause of exercise limitation. Other factors such as respiratory muscle fatigue and central inhibition of neural drive may also contribute to exercise intolerance but their precise role is inconclusive at this time [28-31].

\section{Methodological considerations}

The underlying mechanism for the different behaviour of EELV between the groups could not be determined. By exclusion, differences in expiratory flow limitation and mechanical time constants for lung emptying which could not be measured in this study are probably important. Our patients had a reasonably well-preserved resting IC (75-78\% pred) and results may not be generalisable to patients with a smaller resting $\mathrm{IC}$.

Accurate assessment of dynamic hyperinflation using the IC is based on the assumption that TLC remains constant and that patients are able to inspire to TLC throughout exercise. Stability of TLC during exercise could not be evaluated in this study. However, previous work has confirmed that TLC remains constant during exercise in healthy subjects [32] and in COPD [33]. Studies have also shown that patients with COPD can consistently generate similar peak inspiratory oesophageal pressures during serial IC manoeuvres throughout exercise, despite progressive reduction of the latter as a result of $\mathrm{DH}[34,35]$. Moreover, patients are capable of maximal diaphragm activation during inspiratory efforts to TLC $[28,36]$ even when dyspnoeic at peak exercise [28]. These observations, coupled with recent evidence that IC during cycle exercise is highly reproducible in a large patient population which included the current study sample [5], support our approach for detecting dynamic hyperinflation.

\section{Conclusion}

In conclusion, we have shown that differences in the behaviour of dynamic EELV during exercise in FEV1-matched groups with COPD did not appear to influence exertional dyspnoea intensity or exercise endurance time during high-intensity constant work rate cycle exercise. This study has shown for the first time that critical constraints on $V \mathrm{~T}$ expansion occur at a similar time and $V E$ in patients with moderate-to-severe COPD irrespective of the presence of $\mathrm{DH}$ during exercise. These results support the idea that the prevailing IC and the mechanical constraints on VT as the IRV approaches its minimal value strongly influence dyspnoea intensity and exercise tolerance in COPD, independent of the presence of acute-onchronic $\mathrm{DH}$ during exercise.

\section{SUPPORT STATEMENT}

This study was supported by Boehringer Ingelheim Pharma GmbH \& Co. KG (Ingelheim, Germany). J. Guenette was supported by postdoctoral fellowships from the Natural Sciences and Engineering Research Council of Canada, the Canadian Thoracic Society and the Canadian Lung Association.

\section{STATEMENT OF INTEREST}

Statements of interest for D.E. O'Donnell, and for the study itself, can be found at www.erj.ersjournals.com/site/misc/statements.xhtml

\section{REFERENCES}

1 Laveneziana P, Webb KA, Ora J, et al. Evolution of dyspnea during exercise in COPD: impact of critical volume constraints. Am J Respir Crit Care Med 2011; 184: 1367-1373.

2 O'Donnell DE, Guenette JA, Maltais F, et al. Decline of resting inspiratory capacity in COPD: the impact on breathing pattern, dyspnea and ventilatory capacity during exercise. Chest 2012; 141: 753-762.

3 O'Donnell DE, Hamilton AL, Webb KA. Sensory-mechanical relationships during high-intensity, constant-work-rate exercise in COPD. J Appl Physiol 2006; 101: 1025-1035.

4 O'Donnell DE, Revill SM, Webb KA. Dynamic hyperinflation and exercise intolerance in chronic obstructive pulmonary disease. Am J Respir Crit Care Med 2001; 164: 770-777.

5 O'Donnell DE, Travers J, Webb KA, et al. Reliability of ventilatory parameters during cycle ergometry in multicentre trials in COPD. Eur Respir J 2009; 34: 866-874.

6 Aliverti A, Stevenson N, Dellacà RL, et al. Regional chest wall volumes during exercise in chronic obstructive pulmonary disease. Thorax 2004; 59: 210-216.

7 Vogiatzis I, Georgiadou O, Golemati S, et al. Patterns of dynamic hyperinflation during exercise and recovery in patients with severe chronic obstructive pulmonary disease. Thorax 2005; 60: 723-729.

8 O'Donnell DE, Laveneziana P. The clinical importance of dynamic lung hyperinflation in COPD. COPD 2006; 3: 219-232.

9 O'Donnell DE, Lam M, Webb KA. Spirometric correlates of improvement in exercise performance after anticholinergic therapy in chronic obstructive pulmonary disease. Am J Respir Crit Care Med 1999; 160: 542-549.

10 O'Donnell DE, Voduc N, Fitzpatrick M, et al. Effect of salmeterol on the ventilatory response to exercise in chronic obstructive pulmonary disease. Eur Respir J 2004; 24: 86-94.

11 Peters MM, Webb KA, O'Donnell DE. Combined physiological effects of bronchodilators and hyperoxia on exertional dyspnoea in normoxic COPD. Thorax 2006; 61: 559-567.

12 O'Donnell DE, Fluge T, Gerken F, et al. Effects of tiotropium on lung hyperinflation, dyspnoea and exercise tolerance in COPD. Eur Respir J 2004; 23: 832-840.

13 Maltais F, Hamilton A, Marciniuk D, et al. Improvements in symptom-limited exercise performance over $8 \mathrm{~h}$ with once-daily tiotropium in patients with COPD. Chest 2005; 128: 1168-1178.

14 Laviolette L, Sava F, O'Donnell DE, et al. Effect of obesity on constant workrate exercise in hyperinflated men with COPD. BMC Pulm Med 2010; 10: 33.

15 Laviolette L, O'Donnell DE, Webb KA, et al. Performance during constant workrate cycling exercise in women with COPD and hyperinflation. COPD 2009; 6: 340-351.

16 Gandevia B, Hugh-Jones P. Terminology for measurements of ventilatory capacity; a report to the Thoracic Society. Thorax 1957; 12: 290-293.

17 Borg GA. Psychophysical bases of perceived exertion. Med Sci Sports Exerc 1982; 14: 377-381.

18 O'Donnell DE, Lam M, Webb KA. Measurement of symptoms, lung hyperinflation, and endurance during exercise in chronic obstructive pulmonary disease. Am J Respir Crit Care Med 1998; 158: 1557-1565.

19 Hey EN, Lloyd BB, Cunningham DJ, et al. Effects of various respiratory stimuli on the depth and frequency of breathing in man. Respir Physiol 1966; 1: 193-205. 
20 Garcia-Rio F, Lores V, Mediano O, et al. Daily physical activity in patients with chronic obstructive pulmonary disease is mainly associated with dynamic hyperinflation. Am J Respir Crit Care Med 2009; 180: 506-512.

21 O'Donnell DE, Laveneziana P. Dyspnea and activity limitation in COPD: mechanical factors. COPD 2007; 4: 225-236.

22 O'Donnell DE, Sanii R, Younes M. Improvement in exercise endurance in patients with chronic airflow limitation using continuous positive airway pressure. Am Rev Respir Dis 1988; 138: 1510-1514.

23 O'Donnell DE, Sanii R, Giesbrecht G, et al. Effect of continuous positive airway pressure on respiratory sensation in patients with chronic obstructive pulmonary disease during submaximal exercise. Am Rev Respir Dis 1988; 138: 1185-1191.

24 Palange $\mathrm{P}$, Valli G, Onorati $\mathrm{P}$, et al. Effect of heliox on lung dynamic hyperinflation, dyspnea, and exercise endurance capacity in COPD patients. J Appl Physiol 2004; 97: 1637-1642.

25 Eves ND, Petersen SR, Haykowsky MJ, et al. Helium-hyperoxia, exercise, and respiratory mechanics in chronic obstructive pulmonary disease. Am J Respir Crit Care Med 2006; 174: 763-771.

26 O'Donnell DE, McGuire M, Samis L, et al. General exercise training improves ventilatory and peripheral muscle strength and endurance in chronic airflow limitation. Am J Respir Crit Care Med 1998; 157: 1489-1497.

27 O'Donnell DE, Bain DJ, Webb KA. Factors contributing to relief of exertional breathlessness during hyperoxia in chronic airflow limitation. Am J Respir Crit Care Med 1997; 155: 530-535.
28 Sinderby C, Spahija J, Beck J, et al. Diaphragm activation during exercise in chronic obstructive pulmonary disease. Am J Respir Crit Care Med 2001; 163: 1637-1641.

29 Polkey MI, Kyroussis D, Keilty SE, et al. Exhaustive treadmill exercise does not reduce twitch transdiaphragmatic pressure in patients with COPD. Am J Respir Crit Care Med 1995; 152: 959-964.

30 Luo YM, Moxham J. Measurement of neural respiratory drive in patients with COPD. Respir Physiol Neurobiol 2005; 146: 165-174.

31 Qin YY, Steier J, Jolley C, et al. Efficiency of neural drive during exercise in patients with COPD and healthy subjects. Chest 2010; 138: 1309-1315.

32 Stubbing DG, Pengelly LD, Morse JL, et al. Pulmonary mechanics during exercise in normal males. J Appl Physiol 1980; 49: 506-510.

33 Stubbing DG, Pengelly LD, Morse JL, et al. Pulmonary mechanics during exercise in subjects with chronic airflow obstruction. J Appl Physiol 1980; 49: 511-515.

34 Yan S, Kaminski D, Sliwinski P. Reliability of inspiratory capacity for estimating end-expiratory lung volume changes during exercise in patients with chronic obstructive pulmonary disease. Am J Respir Crit Care Med 1997; 156: 55-59.

35 O'Donnell DE, Bertley JC, Chau LK, et al. Qualitative aspects of exertional breathlessness in chronic airflow limitation: pathophysiologic mechanisms. Am J Respir Crit Care Med 1997; 155: 109-115.

36 Bellemare F, Grassino A. Force reserve of the diaphragm in patients with chronic obstructive pulmonary disease. J Appl Physiol 1983; 55: 8-15. 